\section{Sticky answers to sticky questions}

\author{
John Tyler Bonner
}

Topobiology: An Introduction to Molecular Embryology. By Gerald M. Edelman. Basic Books: 1988. Pp. 240. \$21.95.

THE ideas put forward by Gerald Edelman in his new book will certainly please developmental biologists, for they are entirely in tune with what is generally perceived to be the fundamental problem of development for many years to come. To begin with we all agree that at one end of the scale we must look at the genetics and, more particularly, at the molecular genetics of developmental processes. This is an area that is now advancing at a rapid pace. We also all agree (or at least those who have thought about it) that development is something that must be understood in an evolutionary context, for it is development that has evolved to produce adults of different structure.

\section{Bridging the divide}

Edelman bridges this divide in the following way. First he points out something that has been stressed by many people over the past few years: not all gene effects on development are simply the protein products of transcription and translation, but there are many secondary and tertiary effects, and ones even further removed from the initial proteins that play a vital role in moulding complex organisms. These involve chemical inductors, cell activities of many interesting sorts, including ultimately the activities of cells in the nervous system. Edelman thinks of cells as being the primary actors in carrying out the gene instructions, no matter how distant they may be from the cell actions. Cells can divide, move and die, and all of these processes play a key role. $\mathrm{He}$ is particularly interested in the substances that affect cell adhesion, an area where he has made valuable contributions, and shows how these cell adhesion molecules could carry out distant gene instructions to produce all sorts of tissue configurations including those we generally refer to as pattern. For pattern he also recognizes the importance of the reaction-diffusion models inspired by Alan Turing, but is especially attracted to the mechanochemical models of George Oster, James Murray and Garrett Odell because they can directly include the fluid dynamic properties of the cell.

The book stresses the aristotelian, or perhaps better the waddingtonian notion of epigenesis: the sequence from gene product to ultimate form is the result of a series, or often a network, of causal molecular events which follow one another. This route is, however, well canalized (to continue with Waddington's terminology), and the sequence, even if slightly perturbed, will come back to a consistent sequence and a consistent final form. Furthermore, the currently popular notion of developmental constraints is also stressed. Epigenetic sequences are severely restricted and tend to be conservative because of their past history. Any changes in new developments during the course of evolution are built on the foundation of the earlier ones. For instance, the vertebrate body plan has a common embryology despite a great variety in the form of the adults, as Karl Ernst von Baer made clear many years ago. For any large evolutionary shift (macroevolution) Edelman considers Ernst Haeckel's 'heterochrony' (where the sequence, or time of appearance, during development of different parts of the body can change) to be the explanation, again a position quite in keeping with modern views.

Towards the end of the book there is a discussion of how the nervous system might be formed, and how this might affect behaviour. Here there is an even greater distance between the immediate gene products and the ultimate construction. This is due, as Maxwell Cowan and others have stressed, to the idea that the ultimate connections of the brain are not specified in the genome, but are the result of the functioning of the neuron networks. There is solid support for this notion, not least of which is the evidence for massive cell death; only those cells that happen to be properly hooked up and are able to pass signals remain. Nervous systems and brains are remarkably plastic in both their development and their behaviour, again a feature that emphasizes the great distance generated by the epigenetic causal sequences from genes to a final functional structure. In this case the result is a brain capable of an enormous variety of behaviour not directly controlled by genes.

I have spent so much time giving the message from Edelman's book because I think it is an important one. In general, the ideas are not new - they are either ancient or modern - yet they are very much on the minds of many biologists today. But there are aspects of his excellent summary of this grand theme that are fresh and deserve praise, while there are others (largely involving their presentation) about which I am less enthusiastic.

The most exciting portion of the book (and fortunately it is a sizable one) deals with the glycoproteins that are responsible for the mutual adhesion of cells. Here, Edelman summarizes the work from his own laboratory, but also the work of others on proteins which connect cells to non-cellular matrices and gap junction and desmosome connections between cells. He puts the experimental work into a larger setting which encompasses all of animal development, and does this in an admirable fashion for there is no doubt that cell adhesion plays a fundamental role in development. Most general discussions of epigenesis in the past (including my own) have stressed induction and the passage of chemical signals and responses. Others have appreciated the key role of adhesion in animal development. But I have not seen it put together, from gene to pattern, in such an insightful manner.

\section{Tough reading}

But all is not happy with this book. It is unfortunately not well written. For some perverse reason I am reminded of Alexander Woollcott's remark about the prose of the early mystery writer, Edgar Wallace; that it read as though it had been written on a sewing machine. This description hardly fits Edelman's book, but there is something equally wrong. After all, the story is a straightforward one, yet it is a hard book to read. Relatively minor irritants are the periodic sentences in italics, which reminded me of borrowing someone else's textbook and finding that the owner has underscored what he considers key passages; I kept on having to stop and read the italicized passages twice, for the first time the effect was as though someone had shouted at me through a bull horn and nothing registered.

A more serious problem is the use of acronyms and neologisms, all of which require learning a whole new set of symbols when plain English would have worked remarkably well. Take "topobiology", the very title of the book. Even after re-reading its definitions in different parts of the text I remain puzzled, for it seems to be a code word for some of the main ideas Edelman has to explain. The dozen or so acronyms are even more confusing. For instance Lewis Wolpert's 'positional information' becomes PI (not to be confused with 'principal investigator'). It is rather like reading a Russian novel when one constantly struggles to keep the characters straight. Yet I would not want to discourage the reader. For, despite its imperfections, I found Topobiology a first-rate contribution to developmental biology and believe that the effort needed to read it is well worth the while.

John Tyler Bonner is a Professor in the Department of Biology, Princeton University, Princeton, New Jersey 08544, USA.

- Just published by Chapman and Hall/Van Nostrand Reinhold is the seventh edition of Van Nostrand's Scientific Encyclopedia, edited by Douglas M. Considine. The encyclopaedia now comes in two volumes and contains over 7.000 entries. Price is $f 99, \$ 150$ until the end of this year. $f 115, \$ 175$ thereafter. For a review of the sixth edition see Nature $\mathbf{3 0 3}, 450$ (1983) 